\title{
Cold windows induced airflow effects on the thermal environment for a large single-zone building
}

\author{
Ying Zhang ${ }^{1,2}$, Thomas Olofsson ${ }^{2 *}$, Gireesh $\mathrm{Nair}^{2}$, Chenbo Zhao ${ }^{1}$, Bin Yang ${ }^{1,2}$, Angui $\mathrm{Li}^{1,2}$ \\ 1. School of Building Services Science and Engineering, Xi' an University of Architecture and Technology, Xi' an, Shaanxi \\ 710055, P.R. China \\ 2. Department of Applied Physics and Electronics, Umeå University, SE-90187 Umeå, Sweden
}

\begin{abstract}
With access to modern building technologies and HVAC-systems, it is possible to obtain low energy use and good thermal comfort for complex design, such as large building volumes. However, the situation is different for large single zone buildings with large volumes. They often have insufficient thermal comfort. The problem could be partially attributed to the unwanted airflows due to the cold surfaces, especially the windows. With increased knowledge of the airflow, it is possible to identify suitable renovation strategies in such buildings. In this work, we study a church building with mechanical air change system and floor heating. CFD-simulations with dynamic airflow was conducted based on building geometries and technical data. The validation was based on data from the ventilation control and the space-heating system. The results show how the window-to-wall ratios and the positions of windows affect the thermal comfort. It contributes with knowledge of advantages and disadvantages of different envelope design in the existing environment with floor heating.
\end{abstract}

\section{Introduction}

Large windows and glazed facades on the building envelope can provide more daylight and counteract the negative aspects of long and cold winters in very cold regions [1]. However, large windows and glazed facades also cause thermal sensation complaints due to cold radiation effects and cold natural convective flows along the surface [2].

The airflow velocity downward, along the cold surface, has been investigated by several researchers using different methods, such as analytical and experimental ways. The analysis of boundary layer with free convection on flat plate was treated analytically. The Karman's integrated momentum equation was adopted for the boundary layer [3]. Full-scale experiment was also a way of getting the semi-empirical formula to describe the down draught [1]. As CFD was developed, more details about the flow fields induced by the glazed facades were investigated [4]. For buildings, windows are typical cold surfaces in heating season when the weather is not sunny. Windows are also the weakest link energy-wise in a building. A determinant factor of window design in the transmission of solar radiation into interior space is window-to-wall ratio. However, there was few studies on the relationship of the window-to-wall ratio on the thermal environment in cold seasons for large single-zone building.

In this paper, the CFD method with the turbulent model of the Large Eddy Simulation (LES) was adopted. It was used to simulate the normal flow field of a church based on a large single-zone. A heat deficit often occurs in a cold environment when vasomotor adjustments are not sufficient to compensate for the heat losses from the human body and the body temperature decreases. They were developed especially for a transient or subway application, based on the human heat balance equation [5]. The HDR (Heat Deficit Rate) is used to evaluate the thermal environment with different window-to-wall ratios.

\section{Method}

For a church with a large single-zone, the thermal environment and the effect of airflow along cold walls on the thermal environment was evaluated. This study is based on Computational Fluid Dynamics (CFD), which is a widely used tool during the past two decades in the study of indoor thermal environment [6]. Prior to applying the CFD, a field test lasting for a week had been conducted to validate the simulation.

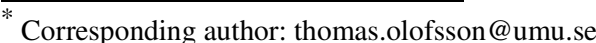




\subsection{Physical model}

The church is located in Umeå, Sweden and was built in 1969. The building space is a combination of multiple interconnected cubes, with a total floor dimension as 32 $\mathrm{m} \times 24.5 \mathrm{~m}$. The highest ceiling is above the altar with 20 $\mathrm{m}$. The height of the main hall is $16 \mathrm{~m}$. The geometry and dimensions are illustrated in Fig.1(a) - (c). The church hall has electric floor heating system. The use of electricity for space heating is substantial. There are 3 outlets with a total exhausting indoor air of $290 \mathrm{~m}^{3} / \mathrm{h}$. To keep the air balance, outside air is drawn into the room through leakages around doors and windows. To simulate the effect of airflow outdoors, on the thermal environment inside via the wind pressure on leakages, a calculation zone was used to cover the physical model, see Fig.1(d). The size of the calculation zone was determined depending on the blocking rate, which is defined as the windward area (perpendicular to the wind direction) of the model is divided by the cross-sectional area of the flow field, as Eq. (1)[7].

$$
S=A_{b} / A_{c}
$$

where $S$ is the blocking rate, $A_{b}$ is the windward area of the model, $A_{c}$ is the cross-sectional area of the flow field. The blocking rate is used to measure whether the computational domain is large enough and whether the surrounding fluid is fully developed. It is reported that when the numerical simulation is carried out, the calculation domain blocking rate should not be more than $3 \%[8,9]$. In this case, the simulation was a single building. The opening on the wall was leeward to the wind and the wind direction angle was constant. The amount of air pushed into the building was focused on instead of the detailed flow field around buildings. So the blocking rate of this paper is $4.7 \%$, which is also acceptable [10].

\subsection{Numerical model validation}

We carried out a field test to measure the air temperature, wall surface temperature and window surface temperature, used the given heat transfer performances of the envelops as the boundary conditions to do the simulation and compared the results of the field and the simulation to validate the numerical model.

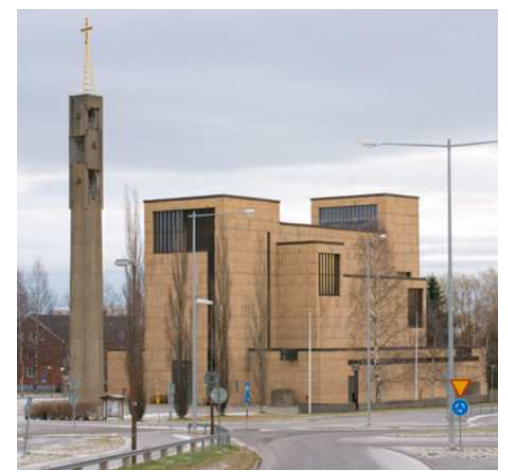

(a)

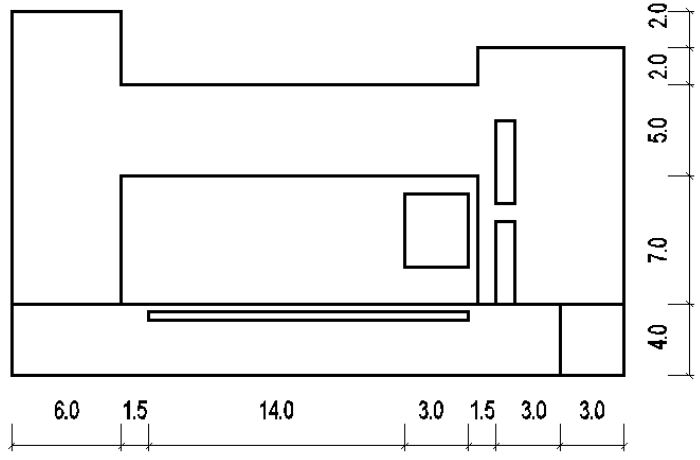

(b)

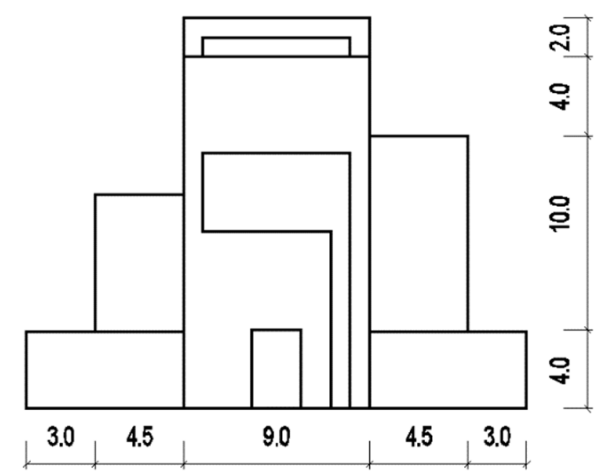

(c)

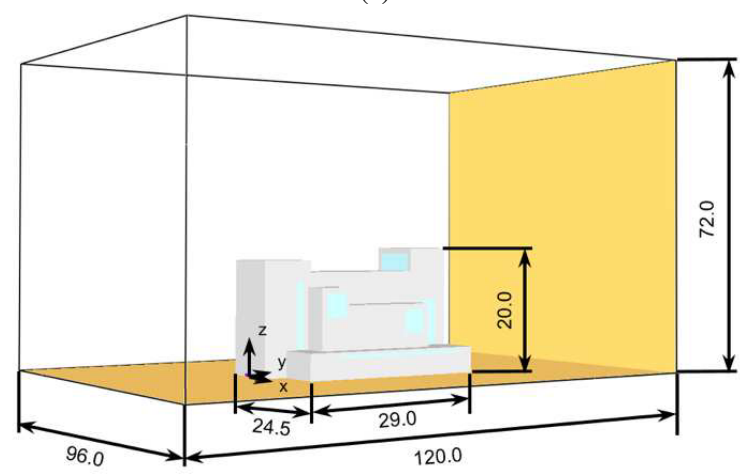

(d)

Fig. 1. Picture and dimensions of the church (unit: $\mathrm{m}$ ) (a) Scene photos; (b) Side view; (c) Main view; (d) Physical model for FDS

The Direct Numerical Simulation (DNS), ReynoldsAveraged Navier-Stokes (RANS) equations, and Large Eddy Simulation (LES) are three common turbulent models. It is possible to perform the DNS if the underlying numerical mesh is fine enough with demands of the huge computational cost. For the RANS, timeaveraged values are obtained, while the LES can predict instantaneous flow characteristics and solve turbulent flow structures [11]. In this study, turbulence was solved using LES.

A field test, including measurements of air temperature, wall surface temperature and window surface temperature, was conducted based on the church to validate the numerical model. The field test lasted for more than a week (from Nov. 18 to 27,2019 ). The results 
of $24 \mathrm{~h}$ with less outdoor temperature variation were selected as boundary conditions and reference results. The averaged outdoor air temperature was $2.2^{\circ} \mathrm{C}$ and air velocity was $2 \mathrm{~m} / \mathrm{s}$ with the negative $y$ coordinate direction, see Fig. 2.

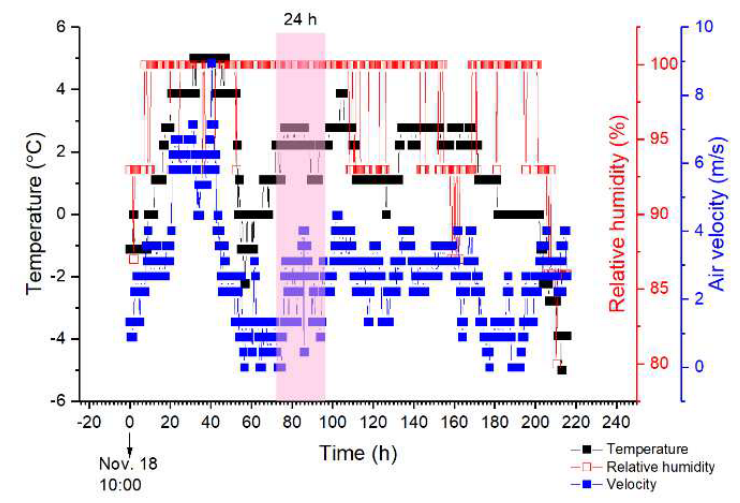

Fig.2. Outdoor climate parameters for the $24 \mathrm{~h}$ selected for simulations

In the simulation, the space heating system was set as a constant surface temperature $\left(23^{\circ} \mathrm{C}\right)$ for the floor. The heat transfer parameters for walls and windows were involved as heat loss rate $0.007 \mathrm{~kW} / \mathrm{m}^{2}$ and $0.03 \mathrm{~kW} / \mathrm{m}^{2}$, respectively. The air temperature, wall surface temperature and window surface temperature for the test and simulation were compared and the test points are also shown in Fig. 3. A1 and A2 are the locations for air temperature at the height of $0.5 \mathrm{~m}$. Win 1 and Win 2 are window surface temperature and they are averaged to be as the Win in the X-axis in Fig. 3. Wall1, Wall2 and Wall3 are wall surface temperature and they are also averaged when compared. The results of the tests and the simulations were found to agree. Therefore, the LES turbulent model was used in this study.

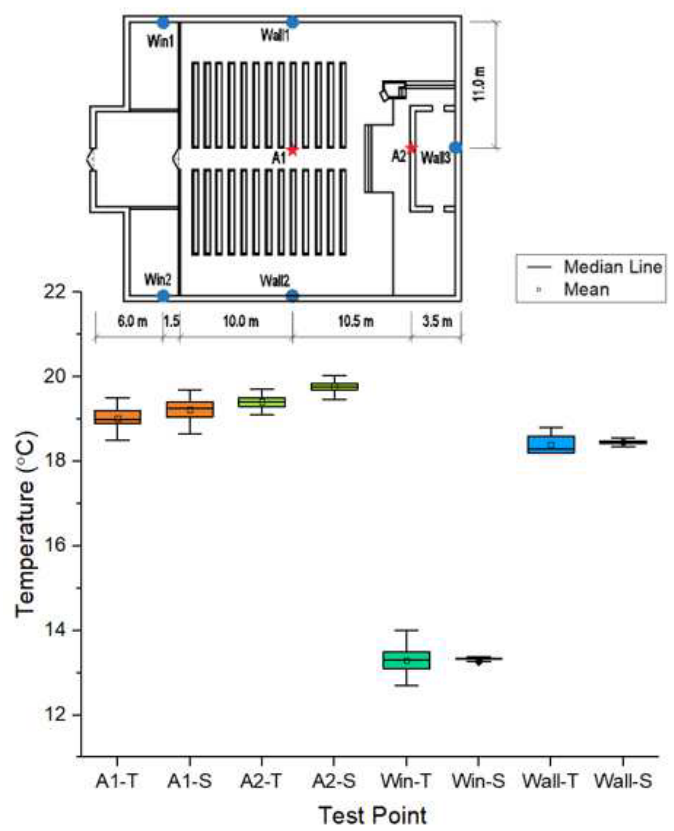

Fig. 3. Comparison of test temperature and simulated temperature (-T represents test results; $-\mathrm{S}$ represents simulated results)

\subsection{Grid size sensitivity study}

Besides the turbulent model, the grid size is another key factor for the CFD. The grid size sensitivity was studied and 5 kinds of grid systems were applied, see Table 1. A grid system that is sufficiently large to provide both acceptable simulation time and acceptable accuracy should be used. For Grid 1 and Grid 4, only one grid size was chosen through the whole model, while there are two zones for Grid 2, Grid 3 and Grid 5. The size of the core zone, which covered the church, for Grid 2 and Grid 3 were different, while their grid sizes were the same. The results of these 5 grid systems were compared and evaluated at two aspects, air and temperature and airflow rate, see Fig. 4. The air temperature of the Grid 2 was $1.2^{\circ} \mathrm{C}$ lower, while the others were very close to each other, shown in Fig. 4(a). However, as to the airflow rate of the church, the results were under-estimated both by the Grid 1 and the Grid 2 during the quasi-steady state, shown in Fig. 4(b). In general, the finer the grid, the higher the accuracy of the calculation results. The results of Grid 3, Grid 4 and Grid 5 were all acceptable. Considering both simulation time and accuracy, Grid 3 was selected, with a total of 933,120 cells.

Table 1. Information on grid systems

\begin{tabular}{|c|c|c|c|}
\hline $\begin{array}{c}\text { Grid } \\
\text { system }\end{array}$ & Grid size (m) & $\begin{array}{l}\text { Core } \\
\text { zone } \\
\text { size } \\
(\mathbf{m})\end{array}$ & $\begin{array}{c}\text { Grid } \\
\text { number } \\
\text { in total }\end{array}$ \\
\hline Grid 1 & $\delta x=\delta y=\delta z=1$ & - & 829,440 \\
\hline Grid 2 & $\begin{array}{c}\delta x_{1}=\delta y_{1}=\delta z_{1}=1 \\
\delta x_{\text {core } 1}=\delta y_{\text {core } 1}=\delta z_{\text {core } 1}= \\
0.5\end{array}$ & $\begin{array}{c}32 \times \\
36 \times \\
24\end{array}$ & 479,232 \\
\hline Grid 3 & $\begin{array}{c}\delta x_{2}=\delta y_{2}=\delta z_{2}=1 \\
\delta x_{\text {core } 2}=\delta y_{\text {core } 2}=\delta z_{\text {core } 2}= \\
0.5\end{array}$ & $\begin{array}{c}48 \times \\
60 \times \\
36 \\
\end{array}$ & 933,120 \\
\hline Grid 4 & $\delta x_{3}=\delta y_{3}=\delta z_{3}=0.5$ & - & $6,635,520$ \\
\hline Grid 5 & $\begin{array}{c}\delta x_{4}=\delta y_{4}=\delta z_{4}=0.5 \\
\delta x_{\text {core } 3}=\delta y_{\text {core } 3}=\delta z_{\text {core } 3}= \\
0.25\end{array}$ & $\begin{array}{c}48 \times \\
60 \times \\
36\end{array}$ & $7,464,960$ \\
\hline
\end{tabular}

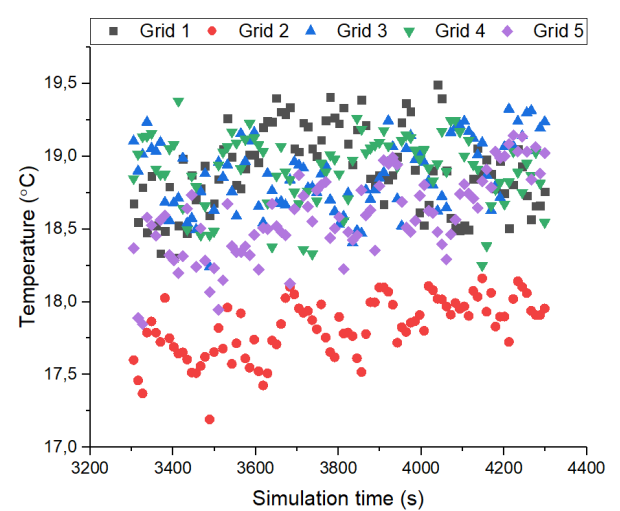

(a) 


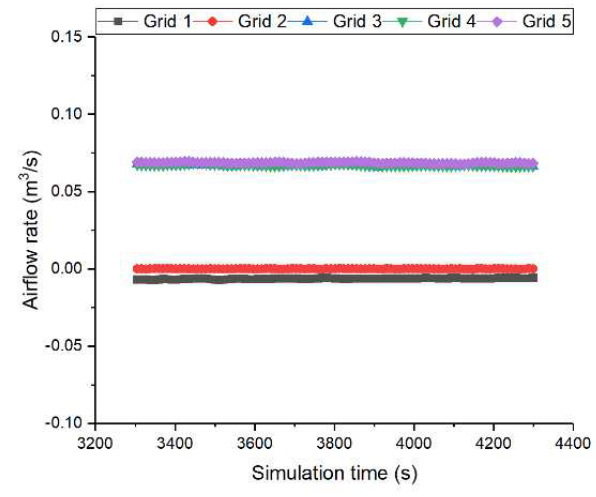

(b)

Fig. 4. Simulation results of different grids

(a) Air temperature of A1 in different grid systems;

(b) Airflow rate of the church

\section{Results and discussion}

To investigate the effect of the thermal environment from the area and the positions of the windows, HDR was used to evaluate the heat transfer between the occupants and the indoor air. ASHRAE 90.1-2007 [12] has determined that Window to Wall Ratio (WWR) of 0.24, a recommended threshold, for enabling optimal indoor daylight and natural ventilation. The larger a window, the more heat or light will pass into the room causing overheating. However, for Nordic countries in cold seasons, large windows will result in cold airflow downward, along the wall, to the occupied zone, causing more complaints about cold sensations, or more energy use to stay warm [13]. Therefore, 6 different windows areas and 5 different positions of the windows were studied. Based on the original window size, we have increase the window areas evenly on the both side of the wall in the CFD simulations. The detailed conditions are shown in Table 2.

Table 2. Working conditions in the CFD calculations

\begin{tabular}{|c|c|c|}
\hline $\begin{array}{c}\text { Case } \\
\text { number }\end{array}$ & $\begin{array}{c}\text { Window to wall } \\
\text { ratio }\end{array}$ & $\begin{array}{c}\text { Distances from } \\
\text { windows bottom to the } \\
\text { floor (m) }\end{array}$ \\
\hline 1 & $25 \%$ & 0 \\
\hline 2 & $20 \%$ & 0 \\
\hline 3 & $15 \%$ & 0 \\
\hline 4 & $8 \%$ & 0 \\
\hline $5^{*}$ & $6.5 \%$ & 0 \\
\hline 6 & $4 \%$ & 0 \\
\hline 7 & $6.5 \%$ & 1.5 \\
\hline 8 & $6.5 \%$ & 4.5 \\
\hline 9 & $6.5 \%$ & 9.0 \\
\hline 10 & $6.5 \%$ & 12.0 \\
\hline
\end{tabular}

* The window area of case 5 is equal to that of the real situation.

\subsection{Thermal environment evaluation with HDR}

HDR was developed for transient environment as an index, derived from the Relative Strain Index. It is defined as Eq. (2) [5],

$$
H D R=-M-\frac{6.43(t-30.6)}{I_{c w}+I_{a}}+28.44-\frac{R I_{a}}{I_{c w}+I_{a}}
$$

where, $M$ is the metabolic rate, $\mathrm{W} / \mathrm{m}^{2} ; I_{c w}$ is the insulation of clothing, based on wet cloth assumption, clo; $I_{a}$ is the insulation effect of air boundary layer, clo; $t$ is the drybulb air temperature, ${ }^{\circ} \mathrm{C} ; t-30.6$ is the difference between dry bulb temperature and average skin temperature, just before a person feels uncomfortably cool, ${ }^{\circ} \mathrm{C} ; R$ is the mean incident radiant heat from sources, other than walls at room temperature, $\mathrm{W} / \mathrm{m}^{2}$.

The simulation and HDR results calculated for outdoor clothes and light clothing are shown in Fig. 5. Here, we discuss the worst situation that there was no other source of heat than floor heating. It meant the heat of occupants, other electric facilities and lights were ignored. For the air temperature and the wall surface temperature were very close to each other, with a difference of about $0.2^{\circ} \mathrm{C}$. Both temperatures decreased as the window to wall ratios gradually increased. The windows surface temperature didn't vary too much, with a range of $0.9^{\circ} \mathrm{C}$. For the HDRs, they increased with rising window to wall ratios. When occupants were still dressed with the heavy clothing indoor, the HDRs were negative. This meant that the occupants gained heat. As the window to wall ratios increased, the gained heat became less and less. The occupants with light clothing indoor, lost heat also from the smallest window to wall ratio. There are two thresholds that should be noted. When the HDR exceeds $28.4 \mathrm{~W} / \mathrm{m}^{2}$, occupants will feel cold. Also $63.1 \mathrm{~W} / \mathrm{m}^{2}$ is assumed to be the threshold for discomfort. Although the HDR for the largest window-to-wall ratio (25\%) didn't exceed $28.4 \mathrm{~W} / \mathrm{m}^{2}$, it does not indicate a more comfortable sensation because body temperature continues to drop, but at a lower rate. Response to heat deficit is cumulative. In addition, the metabolic rate used in the calculation is an averaged value, without taking into account the differences in ages, genders etc. For the same thermal environment, occupants' heat transfers with air depends on the type of clothing they are wearing.

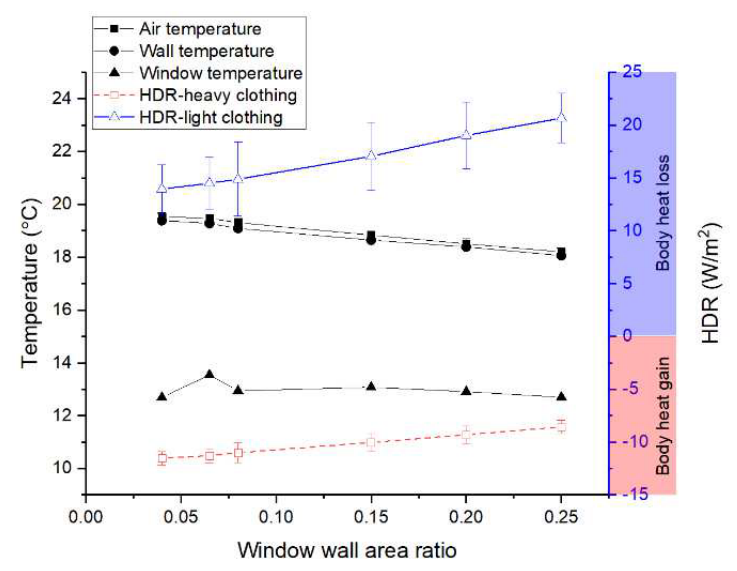

Fig. 5. Mean temperature and HDR for different window to wall ratios 


\subsection{Environmental factors of HDR}

In addition to air temperature, air velocity is another important environmental factor, influencing HDR. Air velocity is not shown in Eq. (2), but it relates to $I_{a}$, the insulation effect of the air boundary layer. For the same air temperature, HDRs decreased as the air velocity decreased, see Fig. 6. The air velocity resulted from the glazed facades due to cold, natural convective flow. Although the air velocity was very small, it caused of thermal discomfort in a relative cold environment. As limit a velocity of $0.15 \mathrm{~m} / \mathrm{s}$ was defined at a distance of 1 $\mathrm{m}$ from the window. Assuming a turbulence intensity of $40 \%$, this requirement corresponds to a draught risk of $20 \%$ [14]. Until now, the problem has often been solved by placing heaters under the windows. We also need to notice the air velocity induced by the cold surfaces. Therefore, to decrease the HDR of occupants, we also need to pay attention to the airflow inside of the building.

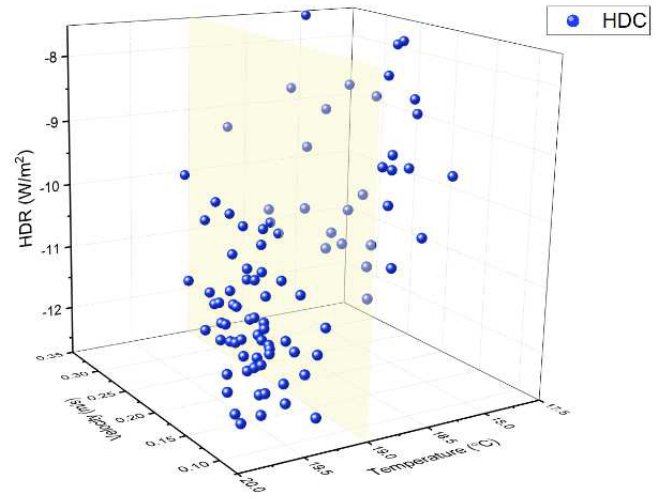

Fig. 6. HDRs with different air temperature and velocity

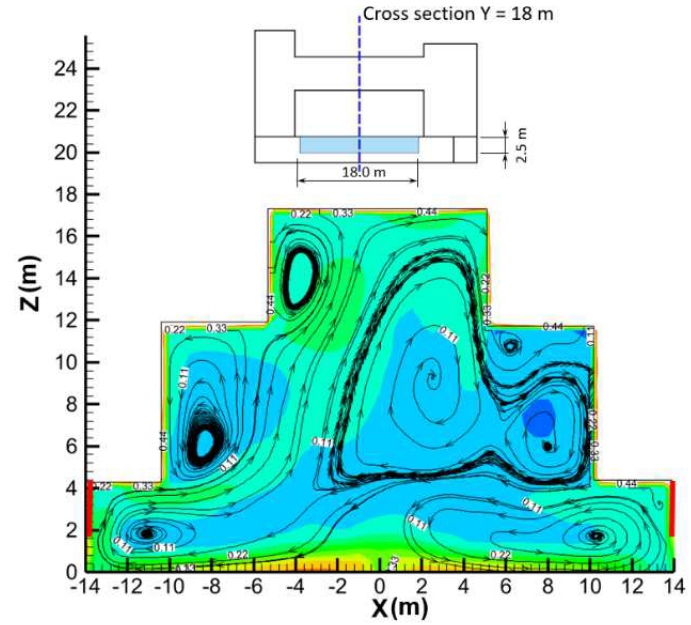

(b) Case 7

\subsection{Effect of windows positions on indoor airflow field}

The airflow fields were affected by the building geometries and cold surfaces, as shown in Fig. 7. The large vortex was determined by the convex geometry and size. As there were sills for each window, the streamline revealed that down draught overflowed over the sill. The sills served as deflectors. So with different window positions, the flow fields were different. However, the window positions were not the most important reason. The temperature difference between the air and the surface and the position of deflectors also take effects [1]. Therefore, when the temperature differences were limited and the position of deflectors were high, the natural convection near the cold window was weak [14]. It only had effect on the partial area. For the occupied zone, the mean air velocity for different windows positions didn't vary much, within $\pm 0.12 \mathrm{~m} / \mathrm{s}$, shown in Fig. 8 .

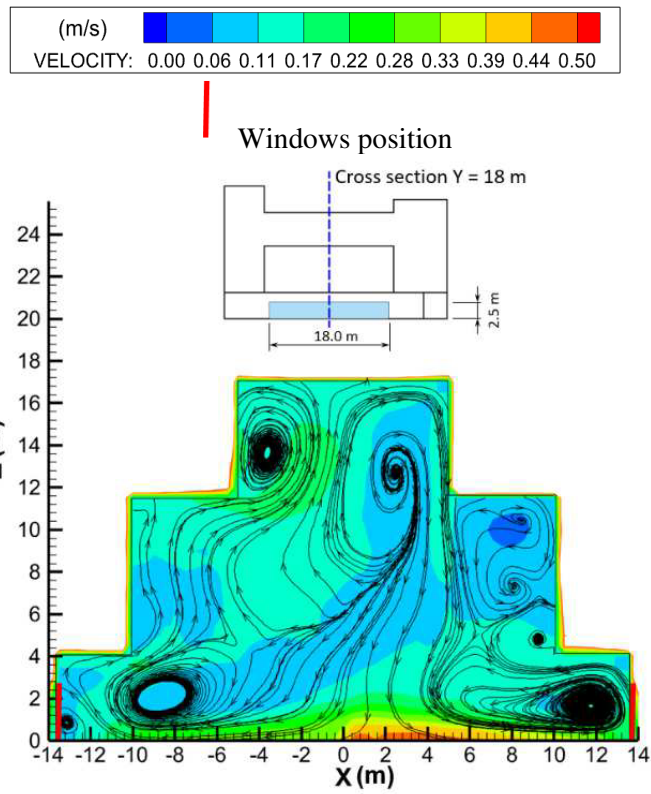

(a) Case 5

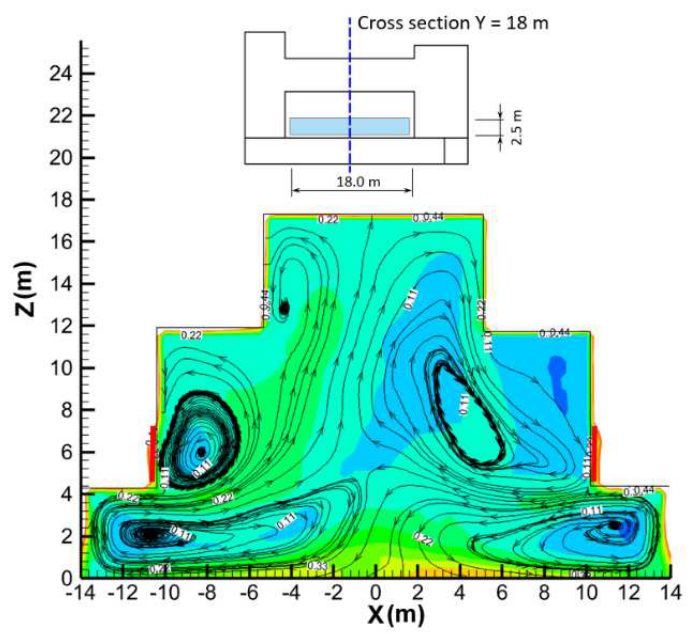

(c) Case 8 


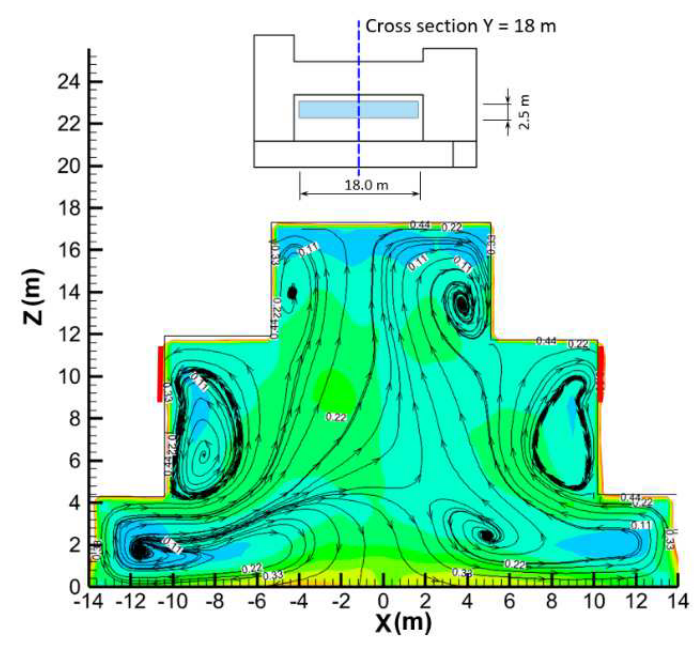

(d) Case 9

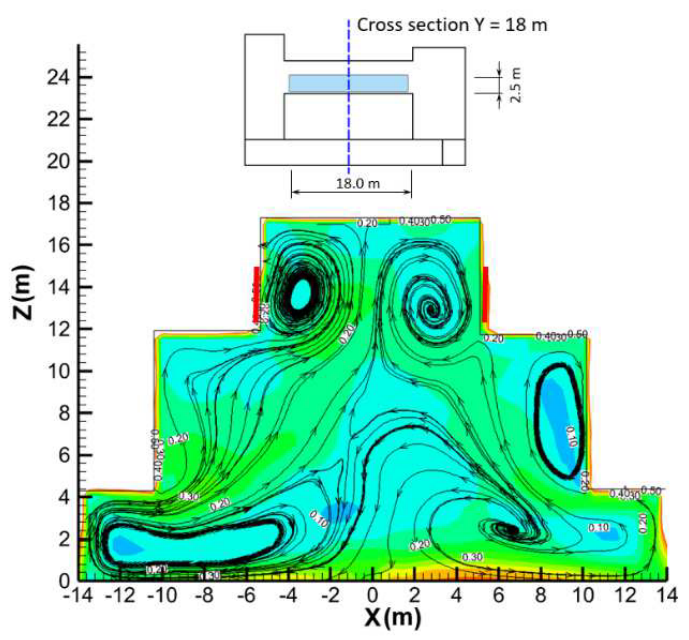

(e) Case 10

Fig. 7. Airflow fields for different windows positions with the same window to wall ratio

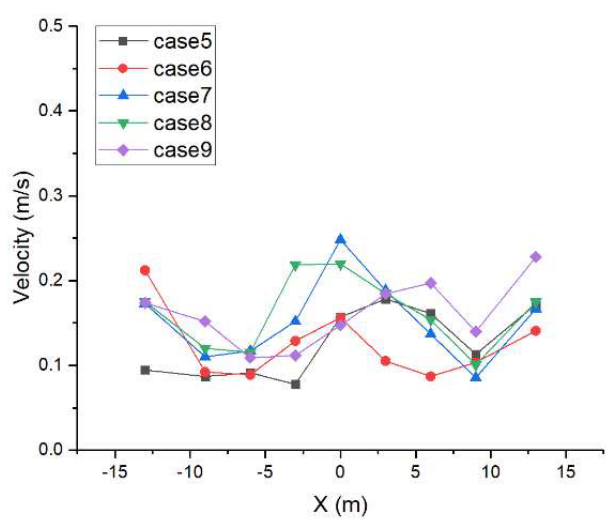

Fig. 8. Air velocity distribution at $2 \mathrm{~m}$ height in occupied zone

\section{Conclusions}

In this study, the turbulent model of the LES was validated and used to simulate the flow field of a church with one large single-zone. HDR was used to evaluate the thermal environment. It was found that the HDRs increased linearly with the window-to-wall ratio. However, the increasing rates were different for two kinds of clothing. For the heavy winter clothes, the increasing rate was $14.33 \mathrm{~W} / \mathrm{m}^{2}$, while for the light clothes, the increasing rate was $32.70 \mathrm{~W} / \mathrm{m}^{2}$. The air velocity also affected the HDR. It decreased when the air velocity decreased. However, the position of windows can only affect the partial airflow indoors, without changing the mean velocity in the occupied zone. This may be due to the limited air temperature difference in the simulations. In the same thermal environment, occupants' heat transfers with air depends on the type of clothing they wear.
The authors acknowledge "Energy pathfinder" project funded by Northern Periphery and Arctic program, Kolarctic CBC Project: KO1089 Green Arctic Building, the Sino-Nordic Research Center for Indoor Environment and Energy (SNRCIEE).

\section{References}

1. P. Heiselberg. Build. Environ 29, 3, (1994).

2. H. Alibaba. Sustainability-Basel 187, 8, (2016).

3. E.R.G. Eckert, T.W. Jackson. NACA Report 1015, (1951).

4. A. Jurelionis, E. Isevičius. J. Civ. Eng. Manag 14, 1, (2008).

5. Subway Environmental Design Handbook. (1976)

6. Q. Chen. Build. Environ 44, (2009).

7. M. Zhao, X. Zhang, X. Zhang, L. Zou, X. Kang. IOP Conf. Ser.: Earth Environ. Sci. 63, 012009 (2017).

8. F. Baetke, H. Werner, H. Wengle. J. Wind Eng. Ind. Aerod 35, (1990).

9. S. A. Bekele, H. Hangan. Wind Struct 5, (2002).

10. P. Fang, M. Gu, J. Tan, G. Luan. J. Arch. Civ. Eng 30, 3, (2013) (in Chinese).

11. R. Gao, A. Li, Y. Zhang, N. Luo. Safety Sci 80, (2015).

12. ANSI/ASHRAE Standard 90.1-2007. Energy Standard for Buildings Except Low-Rise Residential Buildings. (2007).

13. P. Lyons, D. Arasteh, C. Huizenga. Proceedings of 2000 ASHRAE Winter Meeting, Dallas, TX, February 5-9, (2000).

14. T. Rueegga, V. Dorera, U. Steinemann. Energ. Buildings 33 (2001). 